\title{
Sequential Application of Oxygen Therapy Via High-Flow Nasal Cannula and Noninvasive Ventilation in Acute Respiratory Failure: An Observational Pilot Study
}

\author{
Jean-Pierre Frat MD, Benjamin Brugiere MD, Stéphanie Ragot PharmD PhD, \\ Delphine Chatellier MD, Anne Veinstein MD, Véronique Goudet MD, \\ Rémi Coudroy MD, Franck Petitpas MD, René Robert MD PhD, \\ Arnaud W Thille MD PhD, and Christophe Girault MD PhD
}

\begin{abstract}
BACKGROUND: The aim of this study was to evaluate the clinical efficacy of humidified oxygen via high-flow nasal cannula (HFNC) alternating with noninvasive ventilation (NIV) in acute hypoxemic respiratory failure (AHRF). METHODS: We performed a prospective observational study in a 12-bed ICU of a university hospital. All subjects with a $\mathrm{P}_{\mathrm{aO}_{2}} / \mathrm{F}_{\mathrm{IO}}$ of $\leq 300 \mathrm{~mm} \mathrm{Hg}$ with standard mask oxygen and a breathing frequency of $>\mathbf{3 0}$ breaths/min or signs of respiratory distress were included and treated with HFNC first and then NIV. Ventilatory parameters, blood gases, and tolerance were recorded during 2 consecutive sessions of NIV and HFNC. Outcome was assessed after continuation of this noninvasive strategy. RESULTS: Twenty-eight subjects with AHRF were studied, including $23(82 \%)$ with ARDS. Compared with standard oxygen therapy, $\mathrm{P}_{\mathrm{aO}}$ significantly increased from $83(68-97) \mathrm{mm} \mathrm{Hg}$ to $108(83-140) \mathrm{mm} \mathrm{Hg}$ using $\mathrm{HFNC}$ and to $125(97-200)$ mm Hg using NIV $(P<.01)$, whereas breathing frequency significantly decreased. HFNC was significantly better tolerated than NIV, with a lower score on the visual analog scale. The nonintubated subjects received HFNC for 75 (27-127) h and NIV for 23 (8-31) h. Intubation was required in 10 of 28 subjects (36\%), including 8 of 23 subjects with ARDS (35\%). After HFNC initiation, a breathing frequency of $\geq 30 \mathrm{breaths} / \mathrm{min}$ was an early factor associated with intubation. CONCLUSIONS: HFNC was better tolerated than NIV and allowed for significant improvement in oxygenation and tachypnea compared with standard oxygen therapy in subjects with AHRF, a large majority of whom had ARDS. Thus, HFNC may be used between NIV sessions to avoid marked impairment of oxygenation. Key words: acute respiratory failure; acute respiratory distress syndrome (ARDS); noninvasive ventilation; nasal high-flow oxygen therapy; intensive care unit (ICU). [Respir Care 2015;60(2):170-178. @ 2015 Daedalus Enterprises]
\end{abstract}

\section{Introduction}

The use of noninvasive ventilation (NIV) as first-line ventilatory support is well established in patients with a

\footnotetext{
Drs Frat, Brugiere, Chatellier, Veinstein, Goudet, Coudroy, Robert, and Thille are affiliated with the Réanimation Médicale, and Dr Petitpas is affiliated with the Département d'Anesthésie-Réanimation, Centre Hospitalier Universitaire de Poitiers, Poitiers, France. Drs Frat, Ragot, Robert, and Thille are affiliated with the Institut National de la Santé et de la Recherche Médicale, CIC-1402, Université de Poitiers, Poitiers, France. Dr Girault is affiliated with the Medical Intensive Care Department, Centre Hospitalier Universitaire de Rouen, Charles Nicolle University
}

severe exacerbation of COPD ${ }^{1,2}$ and cardiogenic pulmonary edema. ${ }^{3}$ By contrast, conflicting results exist regarding its use in patients with de novo acute hypoxemic respiratory failure (AHRF). Indeed, NIV is more likely to fail in hypoxemic patients, ${ }^{4}$ and the rate of intubation could reach $60 \%$ in unselected patients admitted to ICUs for

\footnotetext{
Hospital, Rouen, France and UPRES EA 3830-IRIB, Rouen University, Rouen, France.

Dr Frat has disclosed a relationship with Fisher \& Paykel Healthcare, which provided some of the material support for this study. The other authors have disclosed no conflicts of interest.
} 
AHRF. ${ }^{5,6}$ Despite these concerns, surveys show that NIV is initiated as first-line ventilatory support in $20-30 \%$ of subjects with AHRF. ${ }^{4,6}$ NIV has even been used in patients with ARDS. ${ }^{7,8}$ However, these patients required prolonged NIV sessions, and poor tolerance to NIV was the reason for intubation in $5-25 \%$ of the cases in hypoxemic patients. ${ }^{7,9-11}$ In a prospective cohort study, poor tolerance was independently associated with an increased risk of intubation. ${ }^{4}$ In case of discomfort, the switch from NIV to standard oxygen therapy could lead to oxygenation impairment and subsequently to endotracheal intubation.

Humidified oxygen therapy via high-flow nasal cannula (HFNC) is a recently available technique delivering a high flow of heated and humidified oxygen through simple nasal prongs. It has been shown that HFNC can help generate low levels of CPAP due to the high flow of fresh gas, ${ }^{12}$ improve comfort and oxygenation, and attenuate signs of respiratory distress compared with standard oxygen therapy. ${ }^{13,14}$ Therefore, HFNC coupled to NIV could be a way to limit prolonged NIV sessions by maintaining adequate oxygenation between them. The aim of our study was to assess comfort, ventilatory parameters, and oxygenation in subjects with AHRF treated consecutively with HFNC and NIV.

\section{Methods}

We conducted a prospective observational pilot study in a 12-bed medical ICU at the University Hospital of Poitiers in France between January 2010 and February 2011. The study protocol was approved by the local research ethics committee of the Jean Bernard University Hospital in Poitiers.

\section{Subjects}

All subjects with de novo AHRF were included if they met both of the following criteria: (1) a breathing frequency of $>30$ breaths/min or clinical signs of respiratory distress, (2) a $\mathrm{P}_{\mathrm{aO}_{2}} / \mathrm{F}_{\mathrm{IO}_{2}}$ of $\leq 300 \mathrm{~mm} \mathrm{Hg}$ after spontaneously breathing oxygen at $15 \mathrm{~L} / \mathrm{min}$ for $>15 \mathrm{~min}$ through a non-rebreathing face mask (Hudson RCI/Teleflex Medical, High Wycombe, United Kingdom). Baselinedelivered $\mathrm{F}_{\mathrm{IO}}$, was measured with a portable oxygen analyzer (MX300, Teledyne Analytical Instruments, City of Industry, California), inserted in a conventional face mask delivering oxygen therapy during spontaneous breathing.

Correspondence: Jean-Pierre Frat MD, Centre Hospitalier Universitaire de Poitiers, rue de la Milétrie, BP 577, 86021 Poitiers Cedex, France. E-mail: jean-pierre.frat@chu-poitiers.fr.

DOI: $10.4187 /$ respcare. 03075

\section{QUICK LOOK}

\section{Current knowledge}

Heated and humidified high-flow oxygen via nasal cannula improves oxygenation by meeting patient inspiratory flow demand and providing a small positive airway pressure. Minute ventilation requirements are also reduced by washout of the upper airway anatomic dead space.

\section{What this paper contributes to our knowledge}

In a small group of subjects with acute hypoxemic respiratory failure, heated and humidified high-flow oxygen by nasal cannula and noninvasive ventilation (NIV) were superior to standard oxygen therapy with respect to oxygenation and ventilatory requirement. High-flow nasal oxygen was better tolerated than NIV with better subject-reported comfort. One-third of all subjects required intubation.

We excluded subjects who had underlying chronic respiratory disease, cardiogenic pulmonary edema, or aplasia; subjects with altered consciousness defined by a Glasgow coma score of $\leq 12$ points or hemodynamic instability defined by systolic arterial blood pressure $<90 \mathrm{~mm} \mathrm{Hg}$, mean arterial blood pressure $<65 \mathrm{~mm} \mathrm{Hg}$, or vasopressor use; and subjects who needed immediate endotracheal intubation. Subjects who met inclusion criteria were consequently included and treated by HFNC followed by NIV.

\section{Adjustments of NIV and HFNC}

After inclusion, subjects were treated successively first with a 2-h session of HFNC and then with a 1-h session of NIV. Sequential application of these 2 treatments was repeated to deliver $16 \mathrm{~h}$ of HFNC and $8 \mathrm{~h}$ of NIV per $\mathrm{d}$ (Fig. 1).

The HFNC device (Optiflow, Fisher \& Paykel Healthcare, Auckland, New Zealand) includes an air-oxygen blender, which allows the accurate adjustment of $\mathrm{F}_{\mathrm{IO}_{2}}$ between 0.21 and 1.0 and delivery of gas flow up to $70 \mathrm{~L} / \mathrm{min}$ through a heated humidifier (MR850, Fisher \& Paykel Healthcare). The gas mixture was routed through a circuit to the subject at a temperature of $37^{\circ} \mathrm{C}$ and an absolute humidity of $44 \mathrm{mg} / \mathrm{L}$ via large-bore bi-nasal prongs. HFNC was initially administered at a gas flow of $50 \mathrm{~L} / \mathrm{min}$ and $\mathrm{F}_{\mathrm{IO}_{2}}$ of 1.0. $\mathrm{F}_{\mathrm{IO}_{2}}$ was adjusted to maintain an $\mathrm{S}_{\mathrm{pO}_{2}}$ of $>92 \%$. Blood gases were measured within $1 \mathrm{~h}$ after HFNC initiation.

NIV was delivered to the subject in a semirecumbent position with a full-face mask (Fisher \& Paykel Health- 


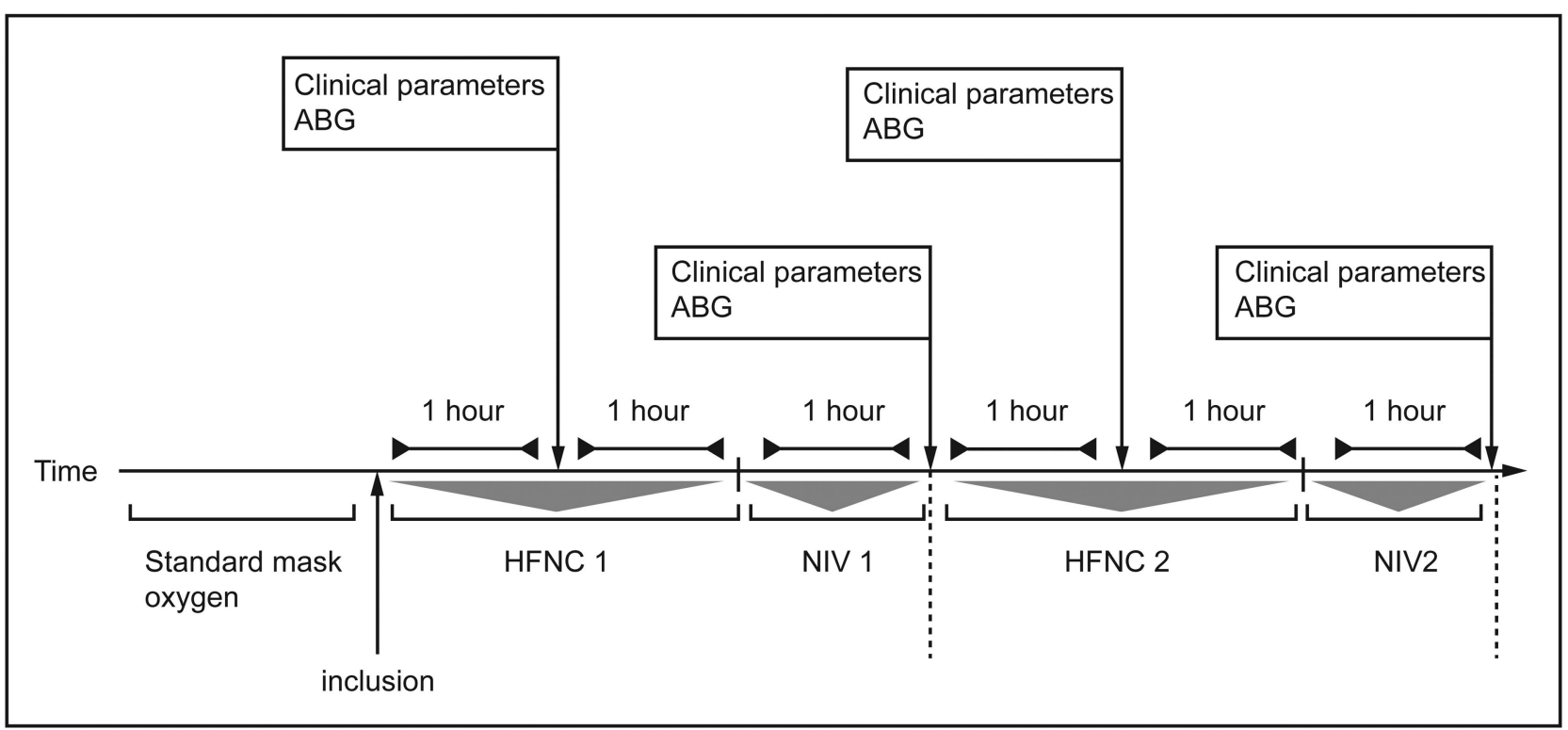

Fig. 1. Design of the study. After inclusion, subjects were treated successively first with a 2-h session of oxygen via high-flow nasal cannula (HFNC) and then with a 1-h session of noninvasive ventilation (NIV). Sequential application of these 2 treatments was repeated to deliver $16 \mathrm{~h}$ of HFNC and $8 \mathrm{~h}$ of NIV per $\mathrm{d}$. Respiratory parameters, ventilatory settings, tolerance, $\mathrm{F}_{\mathrm{IO}_{2}}$, and arterial blood gases (ABG) were recorded at baseline during spontaneous ventilation with a conventional face mask and $1 \mathrm{~h}$ after initiation of HFNC and NIV. These variables were recorded again during the second session of HFNC and NIV.

care) connected to an ICU ventilator with a dedicated NIV mode (Evita XL, Evita 4, or Evita 2 dura, Dräger, Lübeck, Germany) equipped with a heated humidifier (MR850, Fisher \& Paykel Healthcare). Subjects were ventilated by NIV with a pressure support level targeting an expired tidal volume of $6-8 \mathrm{~mL} / \mathrm{kg}$ and a breathing frequency of $<30$ breaths/min. $\mathrm{F}_{\mathrm{IO}_{2}}$ was adjusted to maintain $\mathrm{S}_{\mathrm{pO}_{2}}$ at $>92 \%$ with PEEP of at least $4 \mathrm{~cm} \mathrm{H}_{2} \mathrm{O}$.

\section{Data Collection}

Subjects' characteristics, including etiology of acute respiratory failure, clinical criteria for ARDS, and severity score, were prospectively recorded. The severity of ARDS was stratified using the recent Berlin definition, ${ }^{15}$ according to the value of oxygenation recorded within the first hour after NIV initiation, and classified as mild (201 $\left.\leq \mathrm{P}_{\mathrm{aO}_{2}} / \mathrm{F}_{\mathrm{IO}_{2}} \leq 300 \mathrm{~mm} \mathrm{Hg}\right)$, moderate $\left(101 \leq \mathrm{P}_{\mathrm{aO}_{2}} / \mathrm{F}_{\mathrm{IO}_{2}}\right.$ $\leq 200 \mathrm{~mm} \mathrm{Hg})$, or severe $\left(\mathrm{P}_{\mathrm{aO}_{2}} / \mathrm{F}_{\mathrm{IO}_{2}} \leq 100 \mathrm{~mm} \mathrm{Hg}\right)$. Respiratory parameters, ventilatory settings, tolerance, $\mathrm{F}_{\mathrm{IO}_{2}}$, and blood gases were recorded at baseline during spontaneous ventilation with a conventional face mask and $1 \mathrm{~h}$ after initiation of HFNC and NIV. Tolerance was measured using an unmarked 100-mm visual analog scale that had ends marked with "no constraint" and "intolerable." All these variables were recorded $1 \mathrm{~h}$ after initiation of the second session of HFNC and NIV. The noninvasive strategy using NIV and HFNC between NIV sessions was continued until regression of respiratory distress or intubation occurred.

The following criteria were used for endotracheal intubation: loss of consciousness or psychomotor agitation hindering nursing care; persistent hypotension (defined by systolic arterial blood pressure $<90 \mathrm{~mm} \mathrm{Hg}$ or mean arterial blood pressure $<65 \mathrm{~mm} \mathrm{Hg}$ ) despite fluid resuscitation or need for vasopressors; or 2 of the following criteria: evident worsening of respiratory distress, breathing frequency of $>40$ breaths $/ \mathrm{min}$, abundant secretions, $\mathrm{S}_{\mathrm{pO}_{2}}$ remaining below $92 \%$ despite an $\mathrm{F}_{\mathrm{IO}_{2}}$ of 1.0 , or $\mathrm{pH}$ $<7.35$. NIV failure was defined by the need for endotracheal intubation.

\section{Statistical Analysis}

All data are expressed as mean \pm SD or as median and interquartile ranges (25th and 75th percentiles), and dichotomous variables are reported as number (percentage). Given the small sample of subjects, we used non-parametric tests. Qualitative data were compared using the Fisher exact test, and quantitative data were compared by oneway analysis of variance (Friedman test) for repeated measures or using the Wilcoxon signed-rank test. $P<.05$ was considered statistically significant. Statistical analysis was performed using SAS 9.3 (SAS Institute, Cary, North Carolina). 


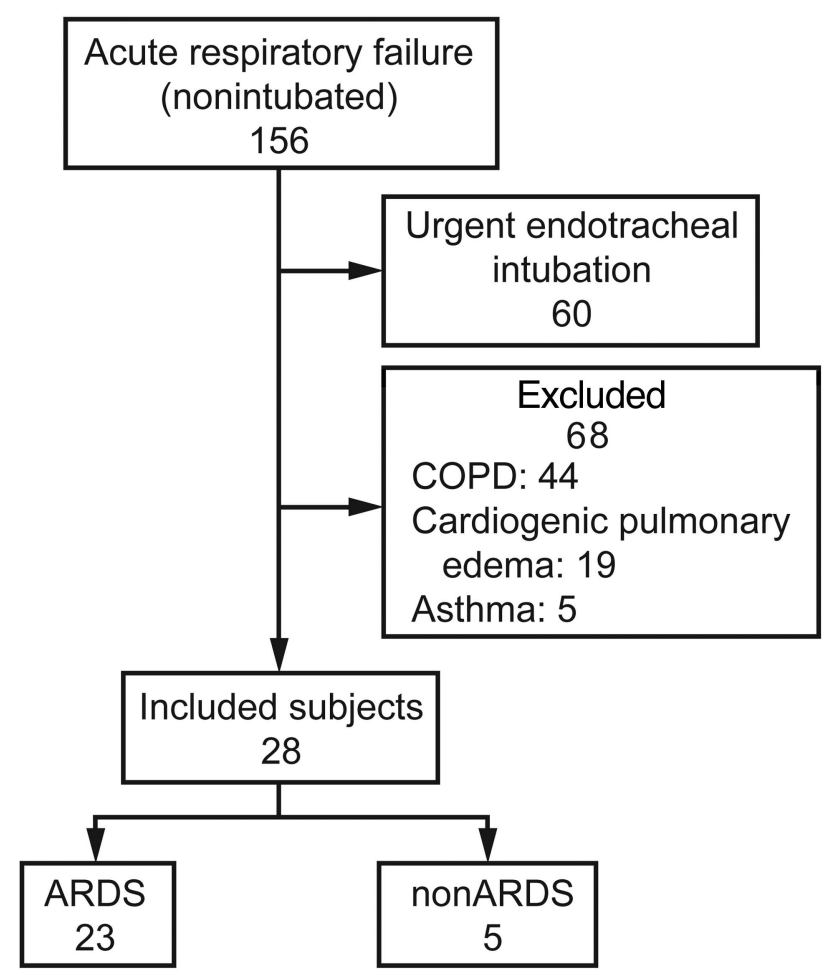

Fig. 2. Flow chart of the study.

A receiver operating characteristic curve was plotted to determine the threshold value of breathing frequency at the end of the first HFNC period, which provided a prediction of intubation with the best sensitivity and specificity.

\section{Results}

After exclusion of subjects who required immediate endotracheal intubation and those with chronic pulmonary disease or cardiogenic pulmonary edema, 28 of 156 subjects admitted in our ICU for respiratory distress were included (Fig. 2). Among them, 23 (82\%) met clinical criteria for ARDS, with a $\mathrm{P}_{\mathrm{aO}} / \mathrm{F}_{\mathrm{IO}_{2}}$ median at NIV initiation of 169 (169-216). Eight subjects were classified as mild ARDS, 14 subjects as moderate ARDS, and one subject as severe ARDS. The characteristics of the subjects at inclusion are shown in Table 1.

At inclusion, median $\mathrm{F}_{\mathrm{IO}_{2}}$ measured through the nonrebreathing face mask was $0.63(0.62-0.63)$ using an oxygen flow of $15(15-15) \mathrm{L} / \mathrm{min}$. Ventilatory settings adjusted during NIV were a pressure support level of 13 (12-15) $\mathrm{cm} \mathrm{H}_{2} \mathrm{O}$, PEEP of $4(4-5) \mathrm{cm} \mathrm{H}_{2} \mathrm{O}$, and $\mathrm{F}_{\mathrm{IO}_{2}}$ of 0.9 (0.6-1.0). During HFNC, $\mathrm{F}_{\mathrm{IO}_{2}}$ was $1.0(0.9-1.0)$, and fresh gas flow was $50(50-50) \mathrm{L} / \mathrm{min}$.
Table 1. Subjects' Characteristics

\begin{tabular}{|c|c|}
\hline Variables & Values \\
\hline Age, median (IQR), y & $61(49-68)$ \\
\hline Males/females, $n(\%)$ & $20 / 28(71)$ \\
\hline BMI, median (IQR), $\mathrm{kg} / \mathrm{m}^{2}$ & $26(23-31)$ \\
\hline Immunosuppression, $n(\%)^{*}$ & $10(36)$ \\
\hline \multicolumn{2}{|l|}{ Etiology of AHRF, $n(\%)$} \\
\hline Community-acquired pneumonia & $13(46)$ \\
\hline Hospital-acquired pneumonia & $5(18)$ \\
\hline Postoperative respiratory failure & $3(11)$ \\
\hline Other $\dagger$ & $7(25)$ \\
\hline \multicolumn{2}{|l|}{ At admission, median (IQR), points } \\
\hline SAPS II & $36(27-41)$ \\
\hline Glasgow coma scale & $15(15-15)$ \\
\hline Breathing frequency, breaths/min & $31(27-37)$ \\
\hline $\mathrm{P}_{\mathrm{aO}_{2}}, \mathrm{~mm} \mathrm{Hg}$ & $83(68-97)$ \\
\hline $\mathrm{F}_{\mathrm{IO}_{2}}$, measured & $0.63(0.62-0.63$ \\
\hline \multicolumn{2}{|c|}{$\begin{array}{l}\text { Ventilatory settings and arterial blood } \\
\text { gas at } 1 \mathrm{~h} \text { of NIV initiation, median (IQR) }\end{array}$} \\
\hline Pressure support, $\mathrm{cm} \mathrm{H}_{2} \mathrm{O}$ & $13(12-15)$ \\
\hline PEEP, $\mathrm{cm} \mathrm{H}_{2} \mathrm{O}$ & $4(4-5)$ \\
\hline $\mathrm{F}_{\mathrm{IO}_{2}}$ & $0.7(0.6-1.0)$ \\
\hline $\mathrm{P}_{\mathrm{aO}_{2}} / \mathrm{F}_{\mathrm{IO}_{2}}$ & $192(158-251)$ \\
\hline $\mathrm{P}_{\mathrm{aCO}_{2}}, \mathrm{~mm} \mathrm{Hg}$ & $40(33-48)$ \\
\hline $\mathrm{pH}$ & $7.43(7.37-7.47$ \\
\hline \multicolumn{2}{|c|}{$\begin{array}{l}\text { *Immunosuppression included hematologic malignancy }(n=5) \text {, immunosuppressive therapy } \\
(n=4) \text {, and acquired immune deficiency syndrome }(n=1) \text {. }\end{array}$} \\
\hline \multicolumn{2}{|c|}{$\begin{array}{l}\dagger \text { Other included ARDS secondary to acute pancreatitis, diffuse alveolar hemorrhage, chest } \\
\text { trauma, and pulmonary embolism. }\end{array}$} \\
\hline \multirow{2}{*}{\multicolumn{2}{|c|}{$\mathrm{IQR}=$ interquartile range }} \\
\hline & \\
\hline \multicolumn{2}{|l|}{$\mathrm{AHRF}=$ acute hypoxemic respiratory failure } \\
\hline \multicolumn{2}{|l|}{ SAPS II = Simplified Acute Physiology Score II } \\
\hline NIV $=$ noninvasive ventilation & \\
\hline
\end{tabular}

\section{Comparison of Clinical Parameters and Oxygenation During Standard Oxygen Therapy, HFNC, and NIV}

$\mathrm{P}_{\mathrm{aO}_{2}}$ increased in 20 of 28 subjects after initiation of HFNC and was significantly higher during HFNC and NIV compared with standard oxygen therapy (Table 2 and Fig. 3). However, $\mathrm{P}_{\mathrm{aO}_{2}} / \mathrm{F}_{\mathrm{IO}_{2}}$ increased only during NIV. Breathing frequency significantly decreased after initiation of HFNC, without further change throughout the ensuing HFNC/NIV sessions. Heart rate significantly decreased after initiation of HFNC and remained stable throughout the ensuing HFNC/NIV sessions.

HFNC was significantly better tolerated than NIV, with a lower score on the visual analog scale of $16(3-46) \mathrm{mm}$ versus $61(41-84) \mathrm{mm}(P=.004)$. Comfort tended to be better during the second session compared with the first session of NIV, but it was not significant, with a median score of $49(14-84) \mathrm{mm}(P=.10)$. No subject developed facial or nasal pressure sores, and no subject needed analgesia or sedation due to NIV intolerance. 
Sequential Application of HFNC and NIV in Acute Hypoxemic Respiratory Failure

Table 2. Evolution of Arterial Blood Gases and Clinical Parameters in All Subjects During HFNC and NIV Sessions

\begin{tabular}{|c|c|c|c|c|c|}
\hline Variables & Baseline & HFNC 1 & NIV 1 & HFNC 2 & NIV 2 \\
\hline $\mathrm{P}_{\mathrm{aO}_{2}}, \mathrm{~mm} \mathrm{Hg}$ & $83(68-97)$ & $108(83-140)^{*}$ & $125(97-200)^{*}$ & $95(75-116) \dagger$ & $121(101-190)^{*}$ \\
\hline $\mathrm{F}_{\mathrm{IO}_{2}}$ & $0.63(0.62-0.63)$ & $1.0(0.95-1.0)^{*}$ & $0.7(0.6-1.0)$ & $1.0(0.6-1.0)^{*}$ & $0.7(0.6-0.8)$ \\
\hline $\mathrm{P}_{\mathrm{aO}_{2}} / \mathrm{F}_{\mathrm{IO}_{2}}, \mathrm{~mm} \mathrm{Hg}$ & $132(119-163)$ & $127(98-166)$ & $192\left(158-251^{*} * \ddagger\right.$ & $128(83-188)$ & $187(155-245)^{*}+\S$ \\
\hline $\mathrm{P}_{\mathrm{aCO}_{2}}, \mathrm{~mm} \mathrm{Hg}$ & $38(33-46)$ & $38(33-45)$ & $40(33-48)$ & $41(32-46)$ & $40(34-49)$ \\
\hline $\mathrm{pH}$ & $7.43(7.38-7.48)$ & $7.42(7.37-7.47)$ & $7.43(7.37-7.47)$ & $7.42(7.37-7.47)$ & $7.40(7.38-7.47)$ \\
\hline $\begin{array}{l}\text { Visual analog scale } \\
\qquad(0 \mathrm{~mm}=\text { no constraint, } \\
100 \mathrm{~mm}=\text { intolerable }), \mathrm{mm}\end{array}$ & NA & $16(3-46) \S$ & $61(41-84)$ & $18(4-31) \S$ & $49(14-61)$ \\
\hline Heart rate, beats/min & $102(95-122)$ & $98(92-112) \dagger$ & $94(78-109) \dagger$ & $87(78-106) \dagger$ & $89(76-108) \dagger$ \\
\hline Systolic arterial pressure, $\mathrm{mm} \mathrm{Hg}$ & $133(121-145)$ & $123(105-143)$ & $126(111-153)$ & $126(117-139)$ & $137(125-148)$ \\
\hline \multicolumn{6}{|c|}{$\begin{array}{l}\text { All variables are expressed as median and interquartile range (25th and } 75 \text { th percentiles). } \\
* P<.01 \text { versus baseline values. } \\
\uparrow P<.05 \text { versus baseline values. } \\
¥ P<.01 \text { versus high-flow nasal cannula (HFNC) values. } \\
\S P<.01 \text { versus the visual analog scale score for noninvasive ventilation (NIV) intolerance. } \\
\text { NA }=\text { not applicable }\end{array}$} \\
\hline
\end{tabular}
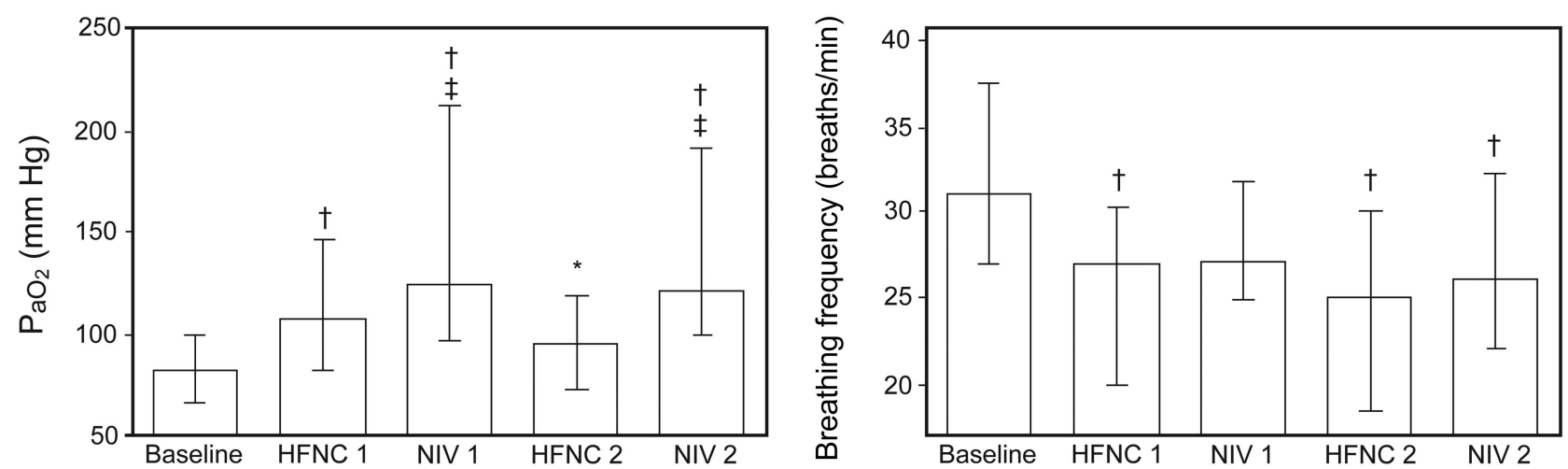

Fig. 3. Evolution of $\mathrm{P}_{\mathrm{aO}}$ and breathing frequency in all subjects from baseline to the end of both oxygen therapy via high-flow nasal cannula (HFNC) and noninvasive ventilation (NIV). $\mathrm{P}_{\mathrm{aO}_{2}}$ increased significantly from baseline to HFNC or NIV sessions $(P<.001)$. Frequency decreased significantly form baseline to HFNC or NIV sessions $(P=.003)$. ${ }^{*} P<.05$ vs baseline; $\dagger P<.01$ vs baseline; $\ddagger P<.01$ vs HFNC. Data are expressed as mean \pm SD.

\section{Outcome and Predictors of Intubation}

Ten of 28 subjects with AHRF (36\%) and 8 of 23 subjects with ARDS (35\%) failed the HFNC/NIV strategy and were subsequently intubated (Table 3 ). The median time between admission and endotracheal intubation was 30 (20-36) h (Fig. 4). The reasons for endotracheal intubation were worsening of respiratory distress $(n=7)$, shock $(n=2)$, and respiratory arrest $(n=1)$. Subjects who required endotracheal intubation had a higher breathing frequency at baseline as well as at $1 \mathrm{~h}$ after initiation of the first HFNC session and at the end of the NIV sessions (Table 3). A breathing frequency of $\geq 30$ breaths $/ \mathrm{min}$ at $1 \mathrm{~h}$ after initiation of the first HFNC session allowed for discrimination between intubated and non-intubated subjects with a sensitivity of $94.1 \%$ and specificity of $87.5 \%$ (area under the receiver operating characteristic curve of 0.88) (Fig. 5). Only one of 8 subjects with a breathing frequency of $\geq 30$ breaths/min underwent successful noninvasive strategy and did not require intubation. Overall, subjects received HFNC for 35 (23-103) h and NIV for 13 (6-30) h, whereas non-intubated subjects received HFNC for 75 (27-127) h and NIV for $23(8-31) h$.

\section{Discussion}

We report the clinical impact of alternating HFNC and NIV in subjects with AHRF, a large majority of whom met the clinical criteria for ARDS. HFNC was better tolerated than NIV; in comparison with standard oxygen therapy, it helped to improve oxygenation and to attenuate signs of 
Table 3. Comparison of Characteristics of Intubated and Non-Intubated Subjects

\begin{tabular}{|c|c|c|c|}
\hline & $\begin{array}{l}\text { Non-intubated } \\
\quad(n=18)\end{array}$ & $\begin{array}{l}\text { Intubated } \\
(n=10)\end{array}$ & $P$ \\
\hline Age, median (IQR), y & $65(51-71)$ & $58(47-63)$ & .29 \\
\hline Males, $n(\%)$ & $14(78)$ & $6(60)$ & .68 \\
\hline BMI, median (IQR), $\mathrm{kg} / \mathrm{m}^{2}$ & $27(22-32)$ & $26(24-27)$ & .84 \\
\hline Immunosuppression, $n(\%)^{*}$ & $6 / 18(33)$ & $4 / 10(40)$ & $>.99$ \\
\hline Etiology of AHRF, $n / n$ total (\%) & & & .49 \\
\hline Community-acquired or hospital-acquired pneumonia & $11 / 18(61)$ & $7 / 10(70)$ & \\
\hline Postoperative respiratory failure & $3 / 18(17)$ & 0 & \\
\hline Other $\dagger$ & $4 / 18(22)$ & $3 / 10(30)$ & \\
\hline ARDS, $n(\%)$ & $15(83)$ & $8(80)$ & $>.99$ \\
\hline Mortality, $n$ & $0 / 18$ & $2 / 10$ & .12 \\
\hline Total duration of mechanical ventilation, median (IQR), d & $4(2-5)$ & $20(17-26) \ddagger$ & .001 \\
\hline ICU stay, median, (IQR), d & $7(5-10)$ & $17(12-24) \ddagger$ & .002 \\
\hline \multicolumn{4}{|l|}{ At admission, median (IQR) } \\
\hline SAPS II on admission & $36(27-39)$ & $36(29-43)$ & .75 \\
\hline Breathing frequency, breaths/min & $29(26-33)$ & $39(30-43) \ddagger$ & .02 \\
\hline $\mathrm{P}_{\mathrm{aO}_{2}} / \mathrm{F}_{\mathrm{IO}_{2}}$ measured at baseline, $\mathrm{mm} \mathrm{Hg}$ & $127(110-136)$ & $154(121-164)$ & .33 \\
\hline $\mathrm{P}_{\mathrm{aCO}_{2}}$, baseline & $39(35-43)$ & $33(29-45)$ & .90 \\
\hline \multicolumn{4}{|c|}{ Ventilatory settings and respiratory parameters at $1 \mathrm{~h}$ of NIV initiation, median (IQR) } \\
\hline Pressure support, $\mathrm{cm} \mathrm{H}_{2} \mathrm{O}$ & $13(12-15)$ & $13(12-15)$ & .58 \\
\hline PEEP, $\mathrm{cm} \mathrm{H}_{2} \mathrm{O}$ & $4(4-5)$ & $4(4-5)$ & .74 \\
\hline $\mathrm{F}_{\mathrm{IO}_{2}}$ & $0.7(0.7-1.0)$ & $0.7(0.7-1.0)$ & .37 \\
\hline $\mathrm{P}_{\mathrm{aO}_{2}} / \mathrm{F}_{\mathrm{IO}_{2}}$ & $190(190-238)$ & $207(207-275)$ & .71 \\
\hline $\mathrm{P}_{\mathrm{aCO}_{2}}, \mathrm{~mm} \mathrm{Hg}$ & $40(34-49)$ & $36(31-44)$ & .72 \\
\hline $\mathrm{pH}$ & $7.42(7.38-7.44)$ & $7.44(7.36-7.48)$ & .83 \\
\hline Breathing frequency, breaths/min & $26(26-28)$ & $33(33-34)$ & .02 \\
\hline \multicolumn{4}{|c|}{ HFNC setting and respiratory parameters at $1 \mathrm{~h}$ of initiation, median (IQR) } \\
\hline Oxygen flow, $\mathrm{L} / \mathrm{min}$ & $50(50-50)$ & $50(50-50)$ & .59 \\
\hline $\mathrm{F}_{\mathrm{IO}_{2}}$ & $1.0(1.0-1.0)$ & $1.0(.01-1.0)$ & $>.99$ \\
\hline $\mathrm{P}_{\mathrm{aO}_{2}} / \mathrm{F}_{\mathrm{IO}_{2}}, \mathrm{~mm} \mathrm{Hg}$ & $122(122-158)$ & $128(128-182)$ & .60 \\
\hline $\mathrm{P}_{\mathrm{aCO}_{2}}, \mathrm{~mm} \mathrm{Hg}$ & $41(35-46)$ & $36(31-41)$ & .13 \\
\hline $\mathrm{pH}$ & $7.41(7.36-7.45)$ & $7.46(7.38-7.48)$ & .39 \\
\hline Breathing frequency, breaths/min & $25(25-27)$ & $31(31-33) \neq$ & .003 \\
\hline Breathing frequency $\geq 30$ breaths/min, $n(\%)$ & $1(5)$ & $7(70) \ddagger$ & .001 \\
\hline $\begin{array}{l}\text { * Immunosuppression included hematologic malignancy, immunosuppressive th } \\
\dagger \text { Other included ARDS secondary to acute pancreatitis, diffuse alveolar hemor } \\
\ddagger \text { There were significant differences between non-intubated and intubated subje } \\
\text { IQR = interquartile range } \\
\text { BMI = body mass index } \\
\text { AHRF = acute hypoxemic respiratory failure } \\
\text { SAPS II = Simplified Acute Physiology Score II } \\
\text { NIV = noninvasive ventilation } \\
\text { HFNC = high-flow nasal cannula }\end{array}$ & $\begin{array}{l}\text { Irome. } \\
\text { m. }\end{array}$ & & \\
\hline
\end{tabular}

respiratory distress. Tachypnea was the only predictive factor for intubation when this NIV strategy was applied.

\section{Effects on Clinical Parameters, Oxygenation, and Comfort}

In the literature, we found that HFNC improved oxygenation and attenuated signs of respiratory distress by decreasing breathing frequency in patients with AHRF. 13,14 These results had already been shown $30 \mathrm{~min}$ after initi- ation of HFNC, ${ }^{13}$ with sustained respiratory improvement for up to $48 \mathrm{~h}$ compared with conventional oxygen therapy. ${ }^{14}$ Our results were obtained with a more severely ill population of hypoxemic subjects, the majority of whom met the clinical criteria for ARDS. Compared with standard oxygen therapy, HFNC can improve oxygenation first by providing a better matching of gas flow in the case of high inspiratory flow, thereby ensuring higher $\mathrm{F}_{\mathrm{IO}_{2}},{ }^{16}$ and second by generating low levels of PEEP that may increase end-expiratory lung volume. ${ }^{12,17} \mathrm{We}$ found that $\mathrm{P}_{\mathrm{aO}_{2}}$ 


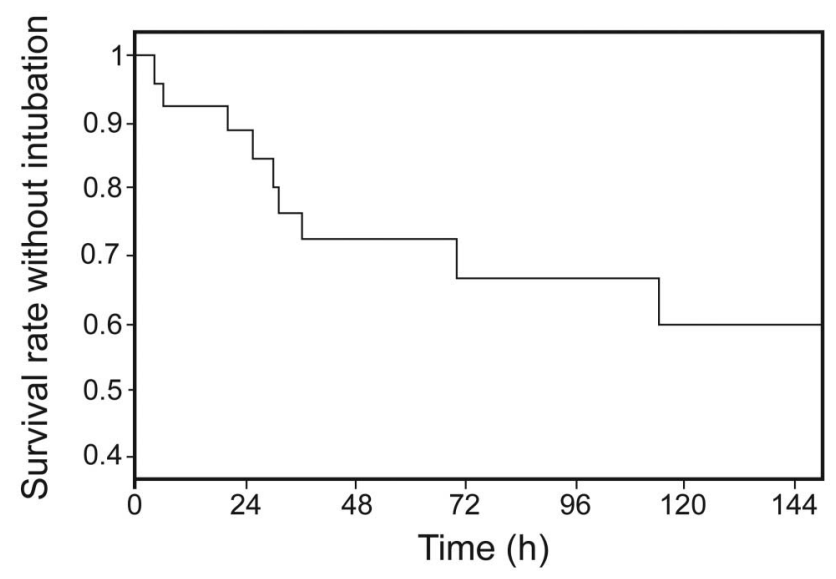

Fig. 4. Time to endotracheal intubation rate in all subjects.

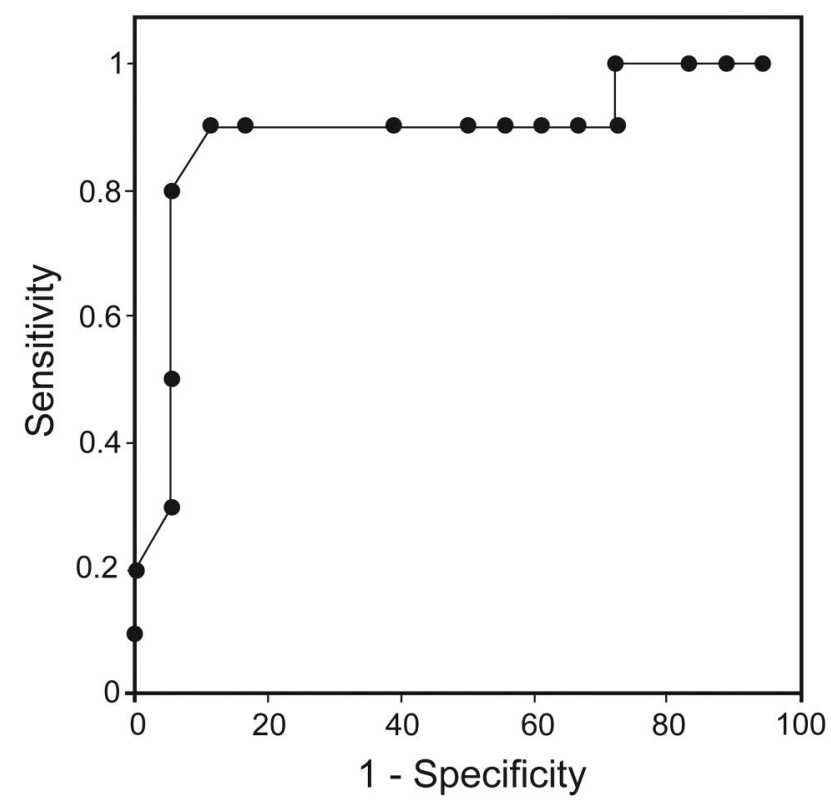

Fig. 5. The area under the receiver operating characteristic curve for breathing frequency at the end of the first HFNC period designed to discriminate intubated from non-intubated subjects was 0.88 . The threshold frequency of 29 breaths/min allowed discrimination between intubated and non-intubated subjects with a sensitivity of $94.1 \%$ and specificity of $87.5 \%$.

significantly increased during HFNC compared with oxygen therapy, whereas $\mathrm{P}_{\mathrm{aO}} / \mathrm{F}_{\mathrm{IO}_{2}}$ remained similar, suggesting that oxygenation improvement was due more to increased $\mathrm{F}_{\mathrm{IO}_{2}}$ than a previously described potential PEEP effect. ${ }^{12}$ In contrast to previous studies ${ }^{7,9,10,18}$ and probably due to our small sample of intubated subjects, $\mathrm{P}_{\mathrm{aO}_{2}} / \mathrm{F}_{\mathrm{IO}_{2}}$ was not associated with an increased risk of intubation. In contrast, low breathing frequency at baseline and its early reduction at the end of HFNC sessions were indeed closely associated with the success of the strategy.
It has been found that patient comfort is higher with HFNC than with oxygen therapy. ${ }^{13,14}$ Not surprisingly, we found that subjects' comfort was also higher during HFNC sessions compared with NIV sessions. Therefore, our strategy of combining NIV and HFNC was prolonged and applied continuously for $>3 \mathrm{~d}$ in non-intubated subjects. Moreover, of the 10 subjects who failed NIV, none were intubated for intolerance to NIV. In the literature, poor NIV tolerance was the reason for intubation in 5\%,9 $9 \%, 10$ and $14 \%^{11}$ of subjects with AHRF and up to $25 \%^{7}$ in subjects with ARDS. In the survey by Demoule et al, ${ }^{4}$ good NIV tolerance was observed in only $7 \%$ of subjects who failed NIV and constituted an independent factor for NIV failure.

\section{Intubation Rate}

Our intubation rate of $36 \%$ is close to the $25-35 \%$ rate reported in randomized controlled trials evaluating NIV in AHRF. ${ }^{11,19}$ However, in these 2 studies, nearly $20-30 \%$ of the subjects received NIV for cardiogenic pulmonary edema, a condition associated with a markedly lower intubation rate. ${ }^{3}$ Moreover, subjects enrolled in such randomized studies are selected, whereas intubation rates up to $45-50 \%$ have been reported in a series of unselected subjects with AHRF of non-cardiac origin ${ }^{8,9}$ and even up to $60 \%$ in prospective cohort studies. ${ }^{5,6}$ In a recent study focusing on ARDS subjects receiving NIV as first-line therapy according to the Berlin ARDS classification, Thille et $\mathrm{al}^{20}$ reported an intubation rate of $61 \%$. These results compare favorably with the $35 \%$ intubation rate in our subjects meeting the clinical criteria for ARDS. In the largest study to date evaluating the impact of HFNC on the outcome of 38 subjects with AHRF, Sztrymf et al ${ }^{14}$ reported an intubation rate of only $24 \%$. However, the proportion of subjects meeting clinical criteria for ARDS was not mentioned. The mortality in our study was also particularly low compared with the literature. ${ }^{15}$ However, our subjects were less severe, selected, and without other organ failure.

\section{Clinical Implications and Limitations}

The first limitation is that all subjects received standard oxygen and then HFNC followed by NIV without return to baseline with standard oxygen therapy. However, we observed a rapid reduction in breathing frequency when switching from standard oxygen to HFNC, and it is highly unlikely, given the high severity of our subjects, that the improvement was related to recovery from respiratory disease.

Another limit was the lack of a controlled group to assess the impact of the strategy combining HFNC with NIV on outcome. Such a multi-center randomized con- 
trolled study, called the FLORALI trial (NCT01320384), is currently ongoing.

The third and more important point is that benefits in terms of oxygenation were less pronounced during HFNC than during NIV. Nevertheless, the more severely ill subjects may require NIV for particularly prolonged sessions. In the study by Antonelli et al, ${ }^{7}$ NIV was continuously applied for a median duration of $42 \mathrm{~h}$. In their study, NIV was applied to $30 \%$ of subjects via a helmet, an interface that has previously exhibited higher tolerance than a face mask. ${ }^{21,22}$ Yet, despite the relatively comfortable interface and the experience of a research team skilled in NIV, the rate of intubation due to NIV intolerance reached $25 \% .^{7}$ Given how difficult it is to maintain continuous and prolonged NIV sessions, we used HFNC as a bridge between them. This association enabled us to pursue the strategy without marked impairment of oxygenation between NIV sessions and with a relatively low intubation rate. However, it has been suggested that NIV may delay intubation and increase the mortality rate of patients with AHRF after NIV failure. ${ }^{9}$ To avoid delaying intubation, we consequently used predetermined criteria for intubation, and NIV was never continued in the event of altered consciousness or shock. Although the use of sedation to continue NIV despite intolerance has been reported over recent years in small studies, ${ }^{23-25}$ we did not give these medications.

\section{Conclusions}

Compared with standard oxygen therapy, HFNC had beneficial effects on oxygenation and respiratory distress symptoms in subjects with AHRF. Despite less oxygenation improvement compared with NIV, HFNC was better tolerated and may be used as a bridge between NIV sessions, with the aim of pursuing a coupled noninvasive strategy of ventilation without a marked impairment of oxygenation.

\section{ACKNOWLEDGMENTS}

We thank Celine Deletage and Carole Guignon for providing technical assistance and Jeffrey Arsham for editing the original manuscript.

\section{REFERENCES}

1. Brochard L, Mancebo J, Wysocki M, Lofaso F, Conti G, Rauss A, et al. Noninvasive ventilation for acute exacerbations of chronic obstructive pulmonary disease. N Engl J Med 1995;333(13):817-822.

2. Keenan SP, Sinuff T, Cook DJ, Hill NS. Which patients with acute exacerbation of chronic obstructive pulmonary disease benefit from noninvasive positive-pressure ventilation? A systematic review of the literature. Ann Intern Med 2003;138(11):861-870.

3. Masip J, Roque M, Sánchez B, Fernández R, Subirana M, Expósito JA. Noninvasive ventilation in acute cardiogenic pulmonary edema: systematic review and meta-analysis. JAMA 2005;294(24):31243130.
4. Demoule A, Girou E, Richard JC, Taillé S, Brochard L. Increased use of noninvasive ventilation in French intensive care units. Intensive Care Med 2006;32(11):1747-1755.

5. Demoule A, Girou E, Richard JC, Taillé S, Brochard L. Benefits and risks of success or failure of noninvasive ventilation. Intensive Care Med 2006;32(11):1756-1765.

6. Schettino G, Altobelli N, Kacmarek RM. Noninvasive positive-pressure ventilation in acute respiratory failure outside clinical trials: experience at the Massachusetts General Hospital. Crit Care Med 2008;36(2):441-447.

7. Antonelli M, Conti G, Esquinas A, Montini L, Maggiore SM, Bello $\mathrm{G}$, et al. A multiple-center survey on the use in clinical practice of noninvasive ventilation as a first-line intervention for acute respiratory distress syndrome. Crit Care Med 2007;35(1):18-25.

8. Agarwal R, Aggarwal AN, Gupta D. Role of noninvasive ventilation in acute lung injury/acute respiratory distress syndrome: a proportion meta-analysis. Respir Care 2010;55(12):1653-1660.

9. Carrillo A, Gonzalez-Diaz G, Ferrer M, Martinez-Quintana ME, Lopez-Martinez A, Llamas N, et al. Non-invasive ventilation in community-acquired pneumonia and severe acute respiratory failure. Intensive Care Med 2012;38(3):458-466.

10. Antonelli M, Conti G, Moro ML, Esquinas A, Gonzalez-Diaz G, Confalonieri M, et al. Predictors of failure of noninvasive positive pressure ventilation in patients with acute hypoxemic respiratory failure: a multi-center study. Intensive Care Med 2001;27(11):17181728.

11. Delclaux C, L'Her E, Alberti C, Mancebo J, Abroug F, Conti G, et al. Treatment of acute hypoxemic nonhypercapnic respiratory insufficiency with continuous positive airway pressure delivered by a face mask: a randomized controlled trial. JAMA 2000;284(18):2352-2360.

12. Parke RL, Eccleston ML, McGuinness SP. The effects of flow on airway pressure during nasal high-flow oxygen therapy. Respir Care 2011;56(8):1151-1155.

13. Roca O, Riera J, Torres F, Masclans JR. High-flow oxygen therapy in acute respiratory failure. Respir Care 2010;55(4):408-413.

14. Sztrymf B, Messika J, Bertrand F, Hurel D, Leon R, Dreyfuss D, Ricard JD. Beneficial effects of humidified high flow nasal oxygen in critical care patients: a prospective pilot study. Intensive Care Med 2011;37(11):1780-1786.

15. ARDS Definition Task Force, Ranieri VM, Rubenfeld GD, Thompson BT, Ferguson ND, Caldwell E, et al. Acute respiratory distress syndrome: the Berlin definition. JAMA 2012;307(23):2526-2533.

16. Sim MA, Dean P, Kinsella J, Black R, Carter R, Hughes M. Performance of oxygen delivery devices when the breathing pattern of respiratory failure is simulated. Anaesthesia 2008;63(9):938-940.

17. Corley A, Caruana LR, Barnett AG, Tronstad O, Fraser JF. Oxygen delivery through high-flow nasal cannulae increases end-expiratory lung volume and reduces respiratory rate in post-cardiac surgical patients. Br J Anaesth 2011;107(6):998-1004.

18. Rana S, Jenad H, Gay PC, Buck CF, Hubmayr RD, Gajic O. Failure of non-invasive ventilation in patients with acute lung injury: observational cohort study. Crit Care 2006;10(3):R79.

19. Ferrer M, Esquinas A, Leon M, Gonzalez G, Alarcon A, Torres A. Noninvasive ventilation in severe hypoxemic respiratory failure: a randomized clinical trial. Am J Respir Crit Care Med 2003;168(12): 1438-1444.

20. Thille AW, Contou D, Fragnoli C, Córdoba-Izquierdo A, Boissier F, Brun-Buisson C. Non-invasive ventilation for acute hypoxemic respiratory failure: intubation rate and risk factors. Crit Care 2013; 17(6):R269.

21. Antonelli M, Conti G, Pelosi P, Gregoretti C, Pennisi MA, Costa R, et al. New treatment of acute hypoxemic respiratory failure: noninvasive pressure support ventilation delivered by helme-a pilot controlled trial. Crit Care Med 2002;30(3):602-608. 
22. Antonelli M, Pennisi MA, Pelosi P, Gregoretti C, Squadrone V, Rocco M, et al. Noninvasive positive pressure ventilation using a helmet in patients with acute exacerbation of chronic obstructive pulmonary disease: a feasibility study. Anesthesiology 2004;100(1): 16-24.

23. Constantin JM, Schneider E, Cayot-Constantin S, Guerin R, Bannier F, Futier E, Bazin JE. Remifentanil-based sedation to treat noninvasive ventilation failure: a preliminary study. Intensive Care Med 2007;33(1):82-87.
24. Clouzeau B, Bui HN, Vargas F, Grenouillet-Delacre M, Guilhon E, Gruson D, Hilbert G. Target-controlled infusion of propofol for sedation in patients with non-invasive ventilation failure due to low tolerance: a preliminary study. Intensive Care Med 2010;36(10): 1675-1680.

25. Rocco M, Conti G, Alessandri E, Morelli A, Spadetta G, Laderchi A, et al. Rescue treatment for noninvasive ventilation failure due to interface intolerance with remifentanil analgosedation: a pilot study. Intensive Care Med 2010;36(12):2060-2065.

This article is approved for Continuing Respiratory Care Education credit. For information and to obtain your CRCE

(free to AARC members) visit

www.rcjournal.com 